\title{
The Effects of Hot Blocks Geometry and Particle Migration on Heat Transfer and Entropy Generation of a Novel I-Shaped Porous Enclosure
}

\author{
Ramin Ghasemiasl $^{1}\left(\mathbb{D}\right.$, Maysam Molana $^{2}\left(\mathbb{D}\right.$, Taher Armaghani $^{3, *}$ and Mohsen Saffari Pour $^{4}(\mathbb{D})$ \\ 1 Department of Mechanical Engineering, West Tehran Branch, Islamic Azad University, \\ Tehran 14687-63785, Iran; ghasemiasl.r@wtiau.ac.ir \\ 2 Department of Mechanical Engineering, Wayne State University, Detroit, MI 48202, USA; molana@wayne.edu \\ 3 Department of Mechanical Engineering, Mahdishahr Branch, Islamic Azad University, \\ Mahdishahr 35618-75915, Iran \\ 4 Department of Mechanical Engineering, Faculty of Engineering, Shahid Bahonar University of Kerman, \\ Kerman 76169-13439, Iran; mohsensp@kth.se \\ * Correspondence: tarmaghani@msh-iau.ac.ir
}

check for updates

Citation: Ghasemiasl, R.; Molana, M.; Armaghani, T.; Saffari Pour, M. The Effects of Hot Blocks Geometry and Particle Migration on Heat Transfer and Entropy Generation of a Novel I-Shaped Porous Enclosure. Sustainability 2021, 13, 7190. https:// doi.org/10.3390/su13137190

Academic Editor:

Fatih Selimefendigil

Received: 4 May 2021

Accepted: 23 June 2021

Published: 26 June 2021

Publisher's Note: MDPI stays neutral with regard to jurisdictional claims in published maps and institutional affiliations.

Copyright: (c) 2021 by the authors. Licensee MDPI, Basel, Switzerland. This article is an open access article distributed under the terms and conditions of the Creative Commons Attribution (CC BY) license (https:/ / creativecommons.org/licenses/by/ $4.0 /)$.

\begin{abstract}
This paper studied the cooling performance of a hot electronic chip using nanofluids (NF) mixed convection, implementing Buongiorno's model of the NF simulation. The NF were assumed water- $\mathrm{Al}_{2} \mathrm{O}_{3}$ nanoparticles (NP) in the range of 0 to $4 \%$ of volume concentration. Six different problems of the combinations of three internal hot blocks, including triangular, square, and circular geometries, and two porous media, including sand and compact metallic powder, were numerically solved. To discretize the governing equations, a finite control volume method was applied. As most of the proposed correlations for the thermophysical properties of the NF were inaccurate, especially for thermal conductivity, a new predictive correlation was proposed using the multi-variable regression method with acceptable accuracy. It was found that the cooling performance improved with any increase in the NP loading. A higher nanoparticle concentration yielded better cooling characteristics, which was $11.93 \%$ for $4 \%$ volume. The sand porous medium also yielded a much higher value of the normalized Nusselt number $(\mathrm{Nu})$ compared to the other medium. The entropy generation (EG) enhancement was maximum for the triangular hot block in a sand porous cavity.
\end{abstract}

Keywords: CFVM; mixed convection; electronic cooling; correlation; thermal conductivity

\section{Introduction}

Nanofluids (NF) are classified as one of the most important candidates for electronic cooling applications. Tremendously high-speed electronic processes in modern processors, along with the inefficient cooling capabilities of conventional fluid like water, lead to open a new scientific horizon between thermal engineers and scientists.

$\mathrm{NF}$, as a relatively new category of heat transfer or working fluids, have attracted the great attention of thermal scientists and engineers in the past two decades across the globe. A tremendous number of scientific papers, reports, and books have been published by researchers from different scientific disciplines like physics, chemistry, nanotechnology, chemical, and mechanical engineering.

Choi and Eastman [1] published the first paper on this issue investigating the cooling performance of the NF comparing pure water as a base fluid. The original idea of suspending a small amount of tiny nanoparticles (NP) in a conventional cooling fluid, nevertheless, belongs to Maxwell [2]. He guessed that the dispersion of metal particles in water could enhance the physical properties drastically. However, he was unsuccessful in preparing a homogenous suspension due to the rapid micro-particle sedimentation.

Nowadays, the NF have been defined as the suspension of nano-scale particles and traditional heat transfer fluids like water and oil aiming at enhancing the thermo-physical 
properties, including viscosity, density, specific heat transfer, and thermal conductivity, compared to the pure base fluid. NF promising properties are proven in a diverse range of applications including, but not restricted to, impingement jets [3], automotive [4], renewable energies [5,6], heating and tempering processes [7-9], heat exchangers [10], nuclear reactors [11,12], electronic chips cooling [7,13], lubrication [14,15], combustion $[16,17]$, and medicine $[18,19]$, etc.

On the other hand, a large amount of industrial applications for enclosures and cavities are known as heat exchangers [20,21], nuclear power [22,23], and Heating, Ventilation and Air conditioning (HVAC) [24-28], etc. Patterson and Imberger [29] implemented a scale analysis in the natural convection of an NF-filled rectangular cavity to examine the possibility of a number of initial flow types. Their results led them to conclude that the transient flow strongly depends on the Prandtl number. However, no effect of the Prandtl number on the steady-state flow was observed.

In an interesting study, Tiwari and Das [30] compared the cooling performance of the $\mathrm{NF}$ and the pure base fluid in a square enclosure, numerically implementing the SemiImplicit Method for Pressure Linked Equations (SIMPLE) algorithm in a finite volume method (FVM). They observed that the flow pattern changed with the NP. They also reported a $100 \%$ enhancement in the maximum Nusselt number $(\mathrm{Nu})$.

A sinusoidal boundary condition in a square cavity involving a water-based NF was investigated numerically by Karim et al. [31]. The impact of a sinusoidal boundary condition on the NF combined convection inside a square cavity implementing a waterbased NF was numerically investigated by Karim et al. [31]. They applied the FVM to examine the influence of the boundary condition on cooling performance. They found out that both the Grashof number $(\mathrm{Gr})$ and the sinusoidal frequency have a considerable effect on the streamlines and isotherms.

A simulation of water-based NF in a porous enclosure by applying the Koo-Kleinstreuer-Li (KKL) model was performed by Mehmood et al. [32] to find the impact of an inclined magnetic field and non-linear radiation at the same time. A significant decrease in the maximum stream function with any decrease in the Darcy number as well as porosity was reported by them. They also observed a noticeable enhancement in the stream function, with an increase in the thermal radiation as well, for the natural convection.

Nithyadevi et al. [33] implemented the FVM to discretize the governing equations for the fluid field in two different physical models to study the NF mixed convection. Suspending the $\mathrm{CuONP}$ in pure water increases the heat transfer drastically due to the impact of a considerable large value of thermal conductivity of the resulting NF.

Some researchers studied the application of the NF-filled cavities in the electronic cooling industry [34-36]. However, there are few published papers focusing on the NF applications in electronic cooling. Many comprehensive investigations are needed to fill this research gap. Most of the frequent geometries of hot electronic chips like triangular ones have not been studied yet.

This paper tries to fill the research gap by understanding the effect of different porous media with investigating the cooling performance of an electronic chip using a mixed convection NF system numerically using the finite volume method. Three shapes for solid blocks (as the electronic chip), including circle, triangle, and square, with the same perimeter, have been studied to find out whether the heat transfer rate is dependent on the geometry or not. It should be noted that the used thermo-fluid configuration is novel. The $\mathrm{Al}_{2} \mathrm{O}_{3}$ nanoparticles were assumed to be suspended in water (up to $4 \%$ volume). Buongiorno's model was employed along with a laminar incompressible and steady flow with a homogenous mixture of the base fluid (water) and suspended nanoparticles. His model has also been employed many times by different researchers across the world [37,38]. The mixture was also assumed as a Newtonian fluid. It was also assumed that there is no temperature difference between the NP and the molecules of water (thermal equilibrium assumption). 
As most of the available correlations for effective thermal conductivity of nanofluids are not accurate and well-defined (as Molana et al. [39] discussed this in detail), a novel correlation for nanofluids thermal conductivity, based on some experimental data with high accuracy, was also provided. Minea et al. [40] also investigated the nanofluids simulation methods comprehensively. More measured data are required to propose a more accurate and comprehensive correlation. One of the most interesting extensions to our model could be inserting a shape factor for different nanoparticle shapes.

This correlation can be used for further investigations. Finally, the optimum case in terms of heat transfer for different geometries and porous media was determined employing the definition of thermal performance criteria (CPT) and the second law of thermodynamics.

\section{Materials and Methods}

Figure 1 shows the schematic of the studied geometries. The I-shaped cavity was assumed lid-driven from the bottom and top. A porous media and the NF also filled the cavity together. Two horizontal walls were assumed moving constantly in opposite directions $(10 \mathrm{~m} / \mathrm{s})$, which are shown by the blue arrows, while other walls were insulated with a constant 306 and $346 \mathrm{~K}$ and were assumed stationary. A hot triangular block was also located at the center of the geometry. All shown dimensions in the figure are in centimeters. The generated mesh network for problem 1 is also shown in Figure 2. The grid base size was $0.5 \mathrm{~mm}$. However, the number of cells per millimeter changed considerably near the hot block to capture the variations in the properties. The total number of cells for triangular, circular, and square hot blocks were $43,200,36,800$, and 42,176 , respectively. Here is the algorithm used in this study:

(a) Select a suitable grid. A grid of $21 \times 21$ was a good start in many cases.

(b) All dependent variables were initialized to zero.

(c) The new boundary values at $(n+1)$ were computed for all walls from the previous values at $(n)$.

(d) The new temperature and the new stream function at $(n+1)$ were computed from previous $(n)$ values at all internal grid points.

(e) The velocity components $\mathrm{U}$ and $\mathrm{V}$ were calculated at $(n+1)$ from the values at $(n)$ explicitly for all the internal grid points.

(f) The same procedure was followed by starting with step (c) to obtain the solution at the next time step at $(n+2)$.

(h) The appropriate value of the relaxation parameter was found to be equal to 0.7, and the iteration process was terminated when the following condition satisfied $\sum_{i, j}\left|x_{i, j}^{\text {new }}-x_{i, j}^{\text {old }}\right| \leq 10^{-7}$, where $x$ is the general dependent variable, which can stand for $\mathrm{U}, \mathrm{V}$, or $\theta$, and $n$ denotes the iteration step. 


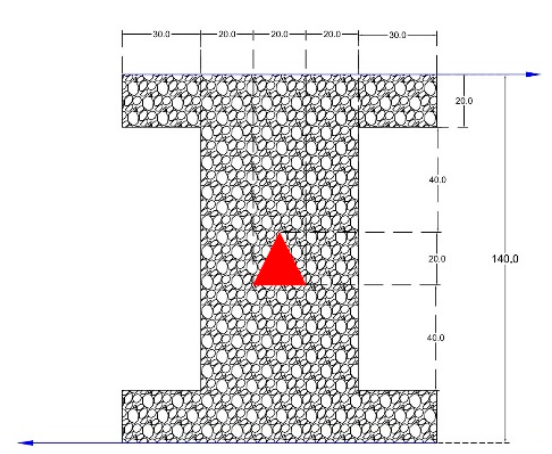

(a)

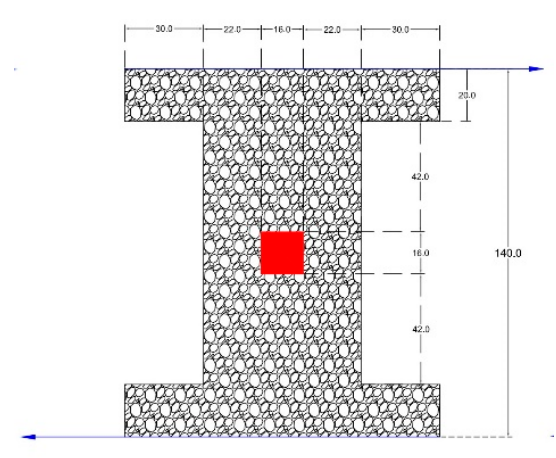

(b)

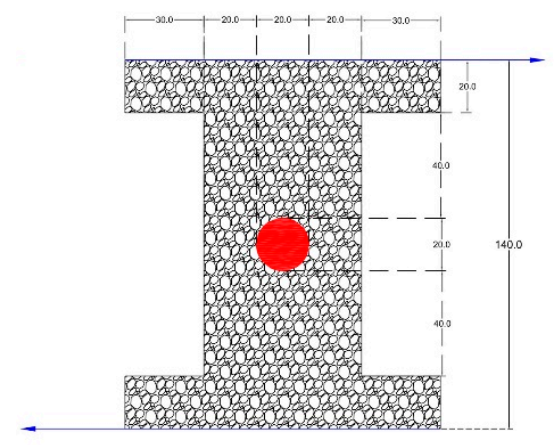

(c)

Figure 1. The problem geometry including a porous media in three different hot blocks (all dimensions are in centimeters). (a) triangular block, (b) square block and (c) circular block.

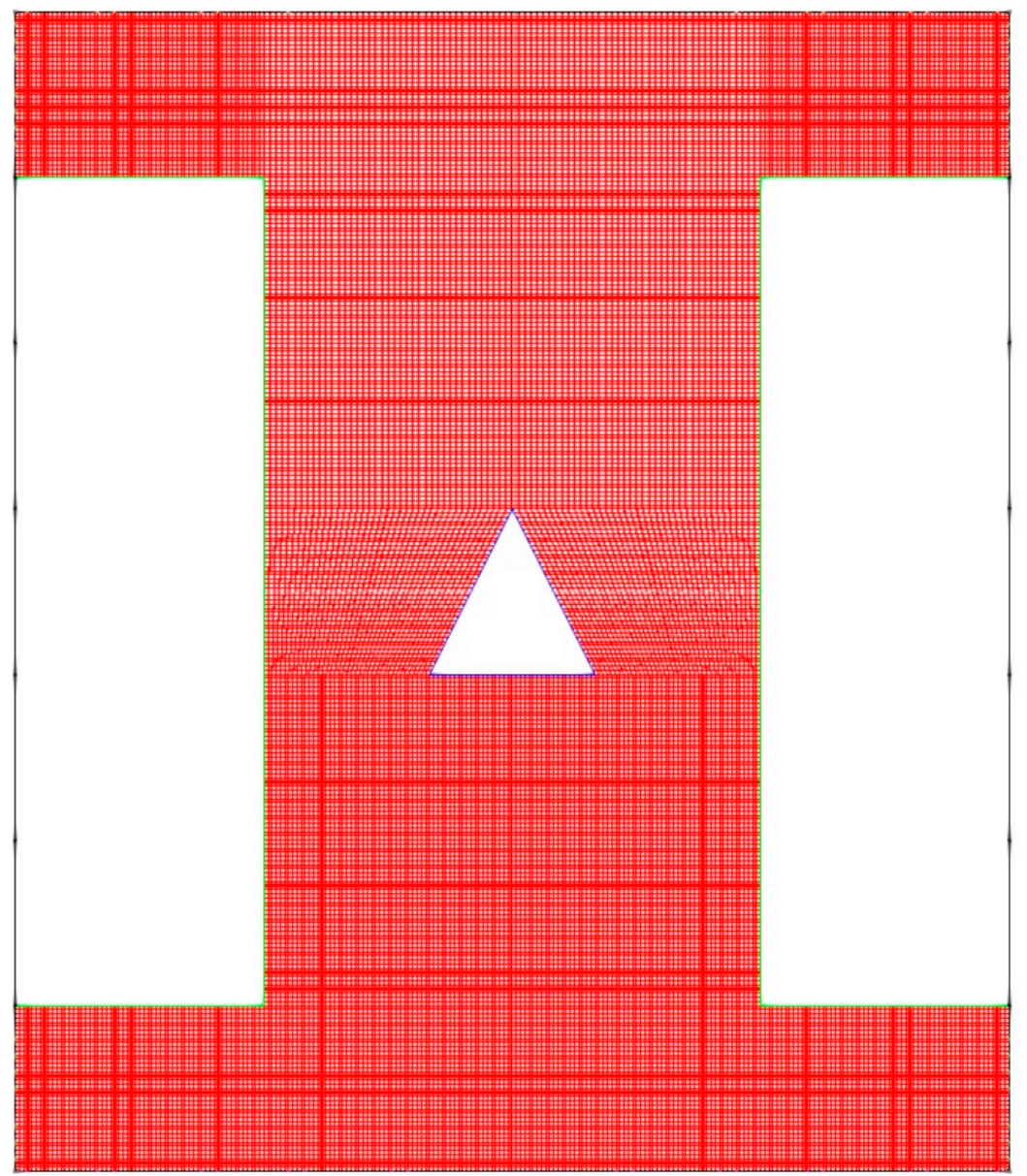

Figure 2. Mesh network for a triangular hot block.

The results available in the literature show that the nanofluids demonstrate superior thermo-physical properties compared to the pure base fluids in the volume concentrations of less than $4 \%$. The main problem for going up is the sedimentation of nanoparticles. Many papers have shown that a higher volume concentration can lead to a rapid sedimentation, followed by having a worse performance compared to the base fluid, in addition to some side effects like corrosion.

The considered NF were $\mathrm{Al}_{2} \mathrm{O}_{3}$-water with a mean diameter of $33 \mathrm{~nm}$ for the NP. Alumina is among the top candidates to be suspended in the base fluids in terms of thermal 
performance. At the same time, it is cheap and highly available. It was assumed that there was no surfactant in the mixture. The reference values of the thermo-physical properties at room conditions are shown in Table 1. To investigate the effect of the porous medium's thermal conductivity on the heat transfer rate, two different porous media were considered, including sand $(3 \mathrm{~W} / \mathrm{m} \cdot \mathrm{K})$ and metallic powder $(60 \mathrm{~W} / \mathrm{m} \cdot \mathrm{K})$. It should be noted that no combination of the mentioned porous media was assumed. Each porous medium was solved separately with the same diffusivity $(0.4)$ and porosity $\left(10-8 \mathrm{~m}^{2}\right)$ but different thermal conductivity. There were also some other assumptions, including no viscous dissipation and no chemical reaction. The most important mechanisms for the nanoparticle slips were assumed to be the thermophoresis and the Brownian diffusion.

Table 1. Thermo-physical properties of the alumina NP and water at the ambient conditions $[41,42]$.

\begin{tabular}{cccccc}
\hline Material & $\boldsymbol{\beta ( \mathbf { 1 } / \mathbf { K } )}$ & $\boldsymbol{\mu}\left(\mathbf{N} \cdot \mathbf{s} / \mathbf{m}^{\mathbf{2}}\right)$ & $\mathbf{k}(\mathbf{W} / \mathbf{m} \cdot \mathbf{K})$ & $\rho$ & $\mathrm{C}_{\mathbf{p}}(\mathbf{J} / \mathbf{k g} \cdot \mathbf{K})$ \\
\hline $\mathrm{Al}_{2} \mathrm{O}_{3}$ & $8.46 \times 10^{-6}$ & - & 40 & 3600 & 765 \\
\hline Water & $2.07 \times 10^{-4}$ & $1.002 \times 10^{-3}$ & 0.598 & 998.3 & 4179 \\
\hline
\end{tabular}

A single-phase approach to model the heat transfer and fluid flow of the nanofluids was unacceptable in most applications due to the homogeneity assumption of the mixture. The effect of particle migration shouldn't be underestimated in modeling. Thermophoresis and Brownian motions are also the most important mechanisms in the nano-scale interactions. Therefore, it was tried to include the above-mentioned mechanisms to leverage the mechanism.

To have a better engineering understanding of thermal management applications, it was also required to evaluate the case in terms of the second law of thermodynamics. Therefore, the entropy generation (EG) was investigated in this paper.

The governing equations, supposed to be solved by OpenFOAM, https: / openfoam. org/, London, United Kingdom (accessed on 25 June 2021), are described in following sections.

The conservation of mass:

$$
\nabla \vec{V}=0
$$

The conservation of momentum:

$$
\nabla\left(\rho_{\mathrm{nf}} \overrightarrow{\mathrm{V}} \times \overrightarrow{\mathrm{V}}\right)=-\left(\nabla \rho_{\mathrm{nf}}\right) \mathrm{g} \cdot \mathrm{h}-\nabla(\mathrm{P})+\mathrm{S}
$$

where $S$ is the source term and was defined as:

$$
\mathrm{S}=-\left(\mu_{\mathrm{nf}} \times \mathrm{d} \times \overrightarrow{\mathrm{V}}+\frac{\rho_{\mathrm{nf}} \times \mathrm{f} \times \overrightarrow{\mathrm{V}}}{2}\right)
$$

The Forchheimer coefficient and Darcy coefficient in Equation (3) are shown by $\mathrm{f}$ and $d$, respectively, and were calculated using Equations (4) and (5) [43]:

$$
\begin{gathered}
\mathrm{d}=\frac{\varepsilon}{\mathrm{K}} \\
\mathrm{f}=\frac{3.5}{\sqrt{150} \times \sqrt{\mathrm{K}} \times \varepsilon^{0.5}}
\end{gathered}
$$

Equation (6) shows the conservation of energy in a porous medium:

$$
\rho_{\mathrm{nf}} \times\left(1-\beta_{\mathrm{nf}}\left(\mathrm{T}-\mathrm{T}_{0}\right)\right) \times \mathrm{C}_{\mathrm{p}, \mathrm{nf}} \times \mathrm{V} \cdot \nabla \mathrm{T}=\nabla\left(\mathrm{k}_{\mathrm{eff}}\right) . \nabla \mathrm{T}+\varepsilon \rho_{\mathrm{nf}} \mathrm{C}_{\mathrm{p}, \mathrm{np}} \times\left[\mathrm{D}_{\mathrm{B}} \nabla \varphi \nabla \mathrm{T}+\mathrm{D}_{\mathrm{T}} \frac{\nabla \mathrm{T} . \nabla \mathrm{T}}{\mathrm{T}}\right]
$$


Equation (6) should be satisfied with the nanoparticle volume concentration [44].

$$
\frac{1}{\varepsilon} \overrightarrow{\mathrm{V}} \cdot \nabla \varphi=\nabla \cdot\left[\mathrm{D}_{\mathrm{B}} \nabla \varphi+\frac{\nabla \mathrm{T}}{\mathrm{T}} \nabla \varphi\right]
$$

Equations (8) and (9) define thermophoresis and the Brownian diffusion coefficients, respectively [45].

$$
\begin{gathered}
\mathrm{D}_{\mathrm{T}}=\left(\frac{0.26 \mathrm{k}_{\mathrm{bf}}}{2 \mathrm{k}_{\mathrm{bf}}+\mathrm{k}_{\mathrm{np}}}\right)\left(\frac{\mu_{\mathrm{nf}}}{\rho_{\mathrm{nf}}}\right) \varphi \\
\mathrm{D}_{\mathrm{B}}=\frac{\mathrm{K}_{\mathrm{b}} \mathrm{T}}{3 \pi \pi_{\mathrm{nf}} \mathrm{d}_{\mathrm{np}}}
\end{gathered}
$$

The total entropy generation and average Nusselt number are given by Equations (10) and (11).

One can calculate the total EG using Equation (10) [46].

$$
\mathrm{S}_{\text {gen }}=\left(\frac{\mathrm{k}_{\mathrm{eff}}}{\mathrm{T}_{0}^{2}}\right) \times\left(\left(\frac{\partial \mathrm{T}}{\partial \mathrm{x}}\right)^{2}+\left(\frac{\partial \mathrm{T}}{\partial \mathrm{y}}\right)^{2}\right)+\frac{\mu_{\mathrm{nf}}}{\mathrm{KT}_{\mathrm{o}}} \times\left(\mathrm{u}^{2}+\mathrm{v}^{2}\right)+\frac{\mu_{\mathrm{nf}}}{\mathrm{T}_{\mathrm{o}}} \times\left(2\left(\left(\frac{\partial \mathrm{u}}{\partial \mathrm{x}}\right)^{2}+\left(\frac{\partial \mathrm{u}}{\partial \mathrm{y}}\right)^{2}\right)\right)+\left(\frac{\partial \mathrm{u}}{\partial \mathrm{x}}+\frac{\partial \mathrm{v}}{\partial \mathrm{y}}\right)^{2}
$$

To calculate the average $\mathrm{Nu}$, one can integrate Equation (11) [46]:

$$
\overline{\mathrm{Nu}}=\int-\left(\frac{\mathrm{k}_{\mathrm{eff}}}{\mathrm{k}_{\mathrm{bf}}}\right) \times\left(\frac{\partial \theta}{\partial \mathrm{n}}\right) \mathrm{dn}
$$

One can calculate the dimensionless temperature, the porous medium's thermal conductivity, and the nanofluids effective density using Equations (12)-(14).

$$
\begin{gathered}
\theta=\frac{\mathrm{T}-\mathrm{T}_{\text {cold }}}{\mathrm{T}_{\text {hot }}-\mathrm{T}_{\text {cold }}} \\
\mathrm{k}_{\text {eff }}=\varepsilon \mathrm{k}_{\mathrm{nf}}+(1-\varepsilon) \mathrm{k}_{\text {solid }} \\
\rho_{\mathrm{nf}}=\varphi \rho_{\mathrm{np}}+(1-\varphi) \rho_{\mathrm{bp}}
\end{gathered}
$$

An empirical correlation was also used for calculating the nanofluids' dynamic viscosity [42]. Many researchers [47,48] successfully employed Ho's correlation for the effective viscosity of nanofluids. Equation (16) shows the definition of the nanofluids' thermal expansion coefficient.

$$
\begin{gathered}
\frac{\mu_{\mathrm{nf}}}{\mu_{\mathrm{bf}}}=1+4.93 \varphi+222.4 \varphi^{2} \\
\rho_{\mathrm{nf}} \beta_{\mathrm{nf}}=(1-\varphi) \rho_{\mathrm{bf}}+\varphi \rho_{\mathrm{np}} \beta_{\mathrm{np}}
\end{gathered}
$$

A new correlation was developed in this study to predict the NF effective thermal conductivity. To that end, 41,370 data points were extracted from the literature for $\mathrm{Al}_{2} \mathrm{O}_{3}$ water NF. The Gauss-Newton multiple regression method, which is a modification of Newton's method to find the minimum of a function, was employed with 46 iterations. The developed equation is as follows:

$$
\mathrm{k}_{\mathrm{eff}}=\mathrm{k}_{\mathrm{bf}} \times\left(1+(1.54115 \times \varphi)^{1.56} \times \frac{0.15581}{\mathrm{~d}_{\mathrm{np}}}\right)
$$

The proposed correlation gave an average absolute error of $4.2 \%$ against the experimental results available in the literature [49]. A comparison of the predicted and measured values is demonstrated in Figure 3. As shown, the correlation was very accurate for predicting the experimental results. 


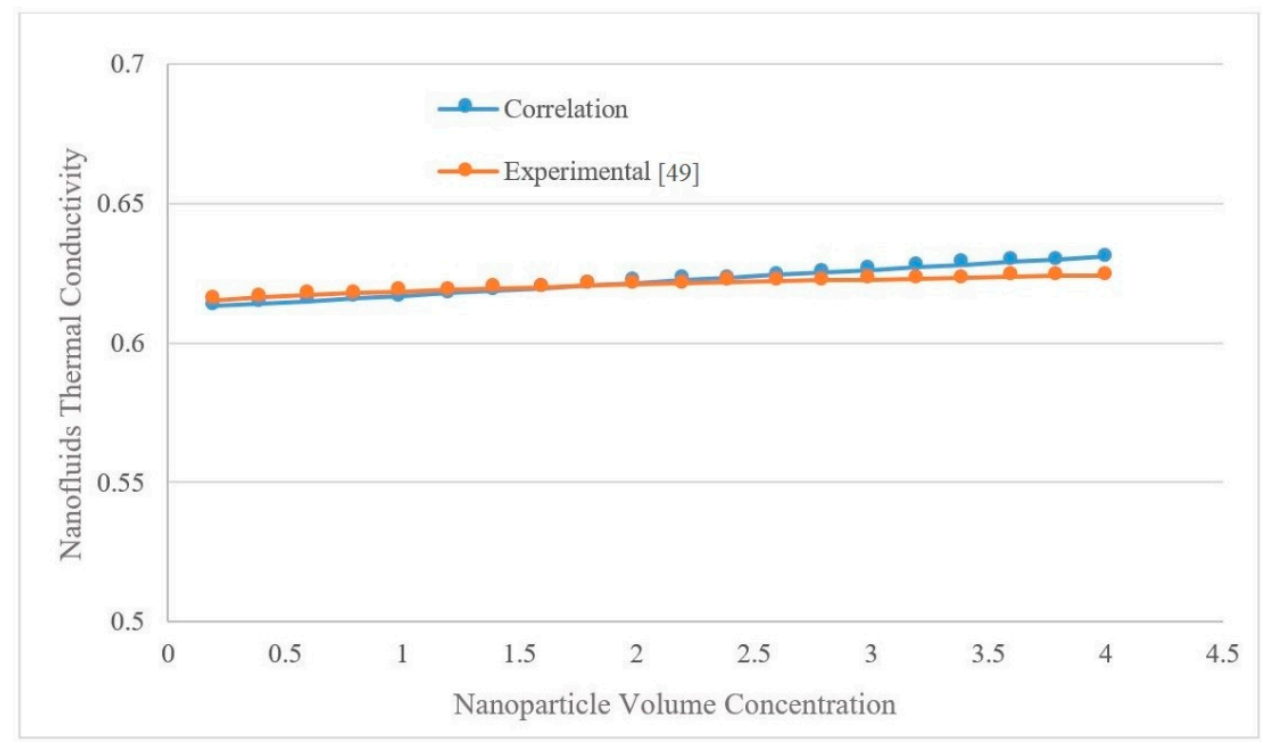

Figure 3. The experimental data and predicted effective thermal conductivity versus the NP volume concentration.

FVM for discretizing the governing equations was used with some additional programmed code in $\mathrm{C}++$ for taking into account the thermophoresis, the Brownian diffusion, and the EG. The mentioned numerical method is based on the integration of governing equations over a finite control volume. Therefore, a set of simple algebraic equations were obtained. Then, the Tri-Diagonal Matrix Algorithm (TDMA) method was used to solve the discretized governing equation employing iterations over the defined domain. Velocity and pressure fields were also coupled by the Semi-Implicit Method for Pressure Linked Equations (SIMPLE) with a defined residual less than $10^{-6}$ for all variables.

The non-uniform grid was used in the computational domains. A two-step validation of the employed numerical method was performed. First, the obtained results for a test case of air flowing in the cavity were compared with the results of Davis [50]. The variations of the Rayleigh number against the Nusselt number for the present work and a well-known reference are shown in Figure 4. The maximum error was around 1.06\%.

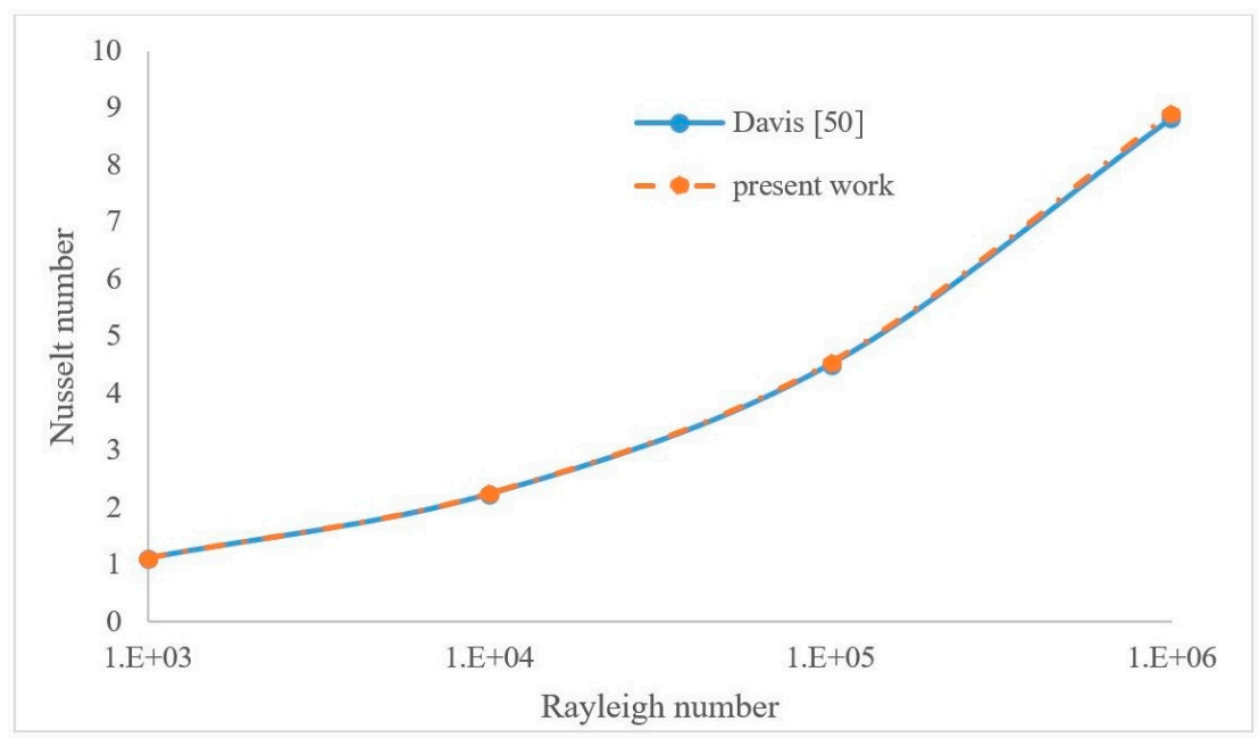

Figure 4. The comparison of the results of the present work with reference. 
As the second step of the validation, the measured data of Nithiarasu et al. [43] were used to compare the results of natural convection of nanofluids in a porous cavity. It was observed that the current numerical method yielded a maximum error of $1.05 \%$, which increased with any decrease in the Rayleigh number and porosity.

Table 2 also shows the results of an extensive procedure of mesh testing to find the proper grid size. There was a negligible difference $(0.32 \%)$ between the resulted average $\mathrm{Nu}$ for $67,600(260 \times 260)$ elements and other mesh sizes. So, the grid size of 6218 nodes and 67,600 elements satisfied the requirements of an accurate solution with proper grid independence.

Table 2. Grid independence test of the present work.

\begin{tabular}{ccccccc}
\hline NP Volume (\%) Concentration & Ra Number & Reference Nu [42] & Mesh Size & Clock Time (Second) & Obtained Nu & Variation \\
\hline 1 & 3 & $5.6 \times 10^{7}$ & 29.0769 & $140 \times 140$ & 334 \\
2 & 3 & $5.6 \times 10^{7}$ & 29.0769 & $160 \times 160$ & 29.2141 \\
3 & 3 & $5.6 \times 10^{7}$ & 29.0769 & $180 \times 180$ & 651 \\
4 & 3 & $5.6 \times 10^{7}$ & 29.0769 & $200 \times 200$ & 940 \\
5 & 3 & $5.6 \times 10^{7}$ & 29.0769 & $220 \times 220$ & 1457 \\
6 & 3 & $5.6 \times 10^{7}$ & 29.0769 & $240 \times 240$ & 2209 \\
7 & 3 & $5.6 \times 10^{7}$ & 29.0769 & $260 \times 260$ & 3781 & 4247 \\
\hline
\end{tabular}

\section{Results and Discussion}

The results of such study are presented in three cases of different hot blocks, including triangular, square, and circular, as well as two different porous media, metallic powder and sand, in this section. Figure 5 shows the streamlines of $4 \%$ volume water- $\mathrm{Al}_{2} \mathrm{O}_{3} \mathrm{NF}$ in two cases of porous media, including compact metallic powder and sand for different geometries of hot blocks. It is clear that the distribution of the streamlines on the right side of the hot block was more uniform than on the left side, especially for the compact metallic powder (Figure $5 b, d, e)$. As it is shown, the flow field in the metallic-based porous medium was more symmetrical than that of the sand-based porous medium due to the high portion of convection in the metallic case. The other finding was that, due to the self-symmetry of the circle and square, the corresponding flow fields were more uniform and symmetrical than that of the triangle case. Furthermore, it was experienced that the square cavities usually gave more symmetrical results than other novel geometries like I-shaped or E-shaped.

Figure 6 shows the temperature contours of $4 \%$ volume of the NF in three different hot blocks in two cases, including sand (a), (c), (e) and compact metallic powder (b), (d), (f). There was an elongation in the temperature contours from the top-left area to the bottomright of the porous media due to the two driven lids for all cases. The low permeability for sand-based porous media (a), (c), (e) led to a small temperature distribution around the hot block. The compact metallic powder gave a more elongated temperature distribution than the sand. 


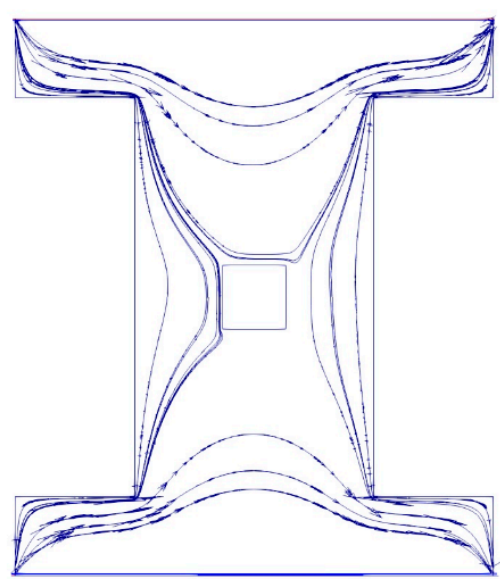

(a)

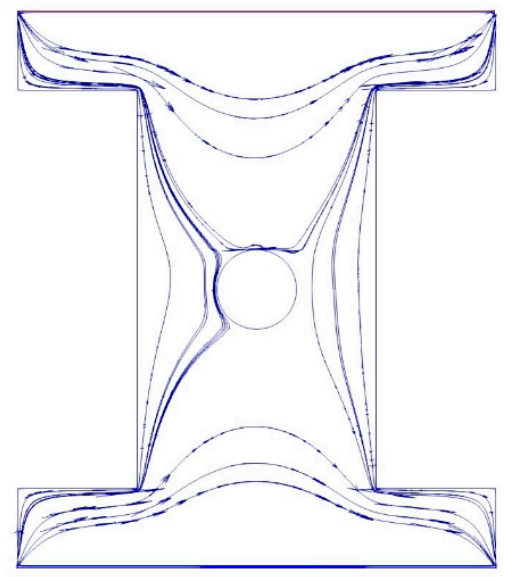

(c)

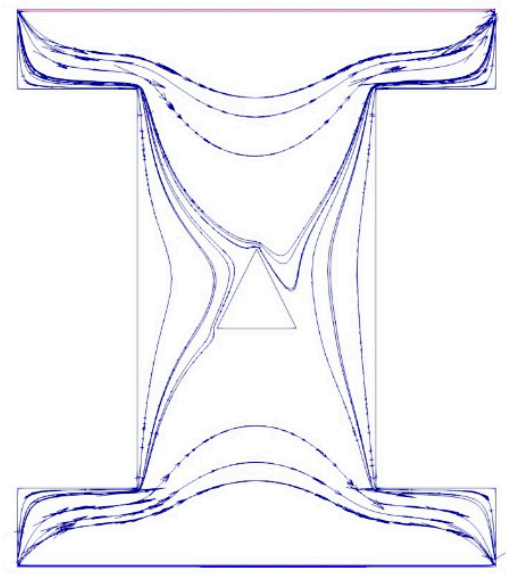

(e)

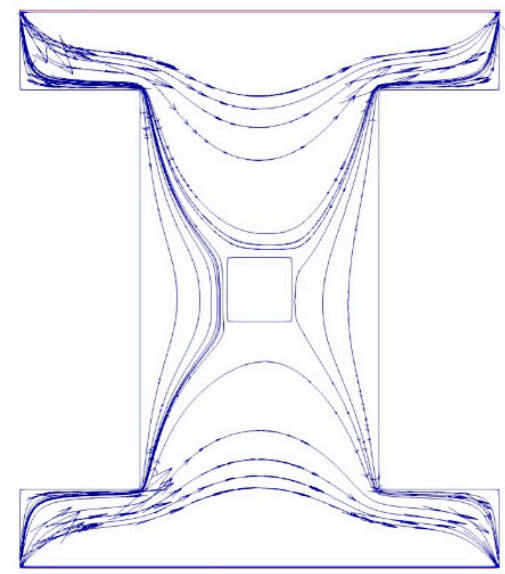

(b)

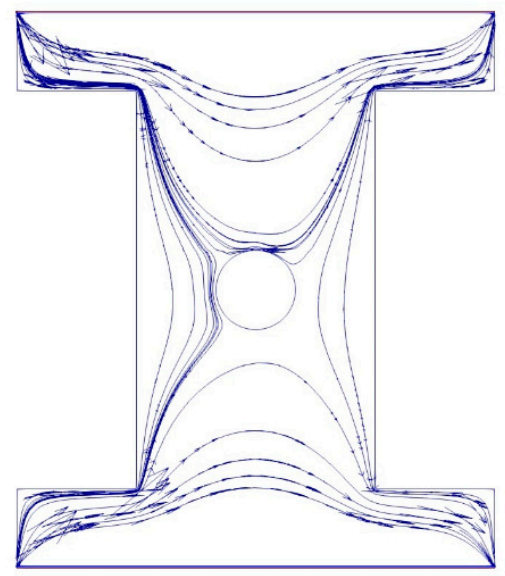

(d)

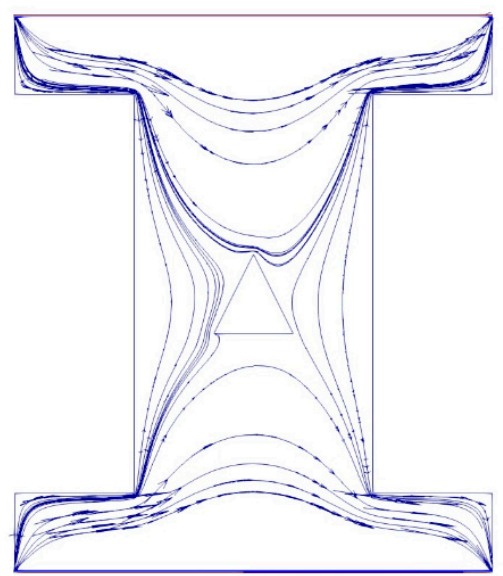

(f)

Figure 5. The streamlines of the $4 \%$ volume of the NF in the sand $(\mathbf{a}, \mathbf{c}, \mathbf{e})$ and compact metallic powder $(\mathbf{b}, \mathbf{d}, \mathbf{f})$ for different geometries of hot blocks. 


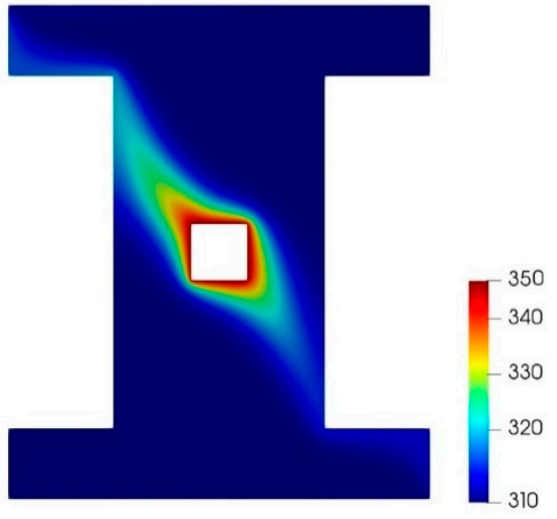

(a)

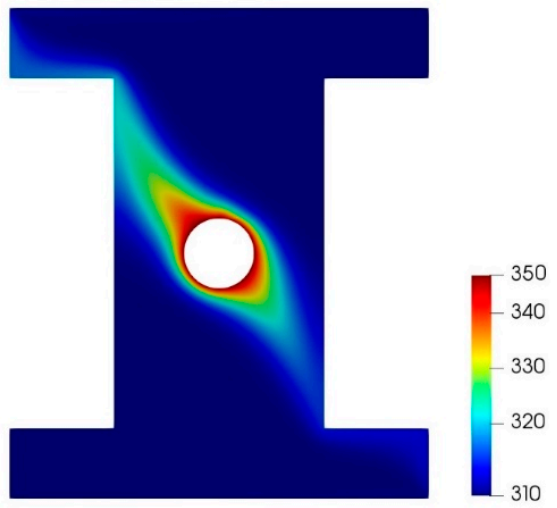

(c)

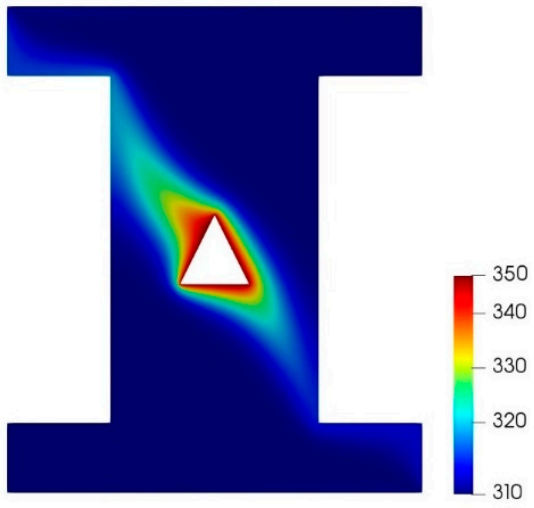

(e)

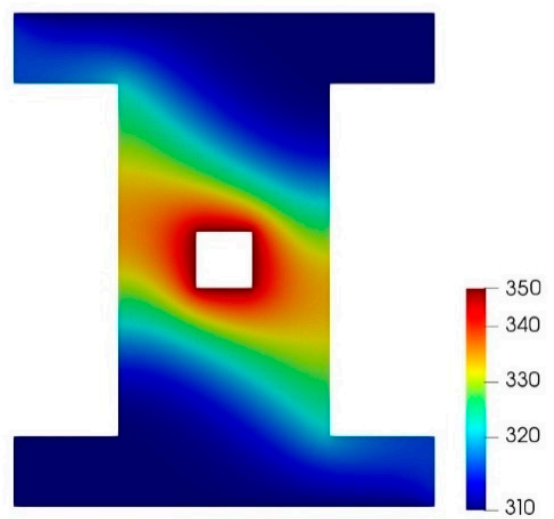

(b)

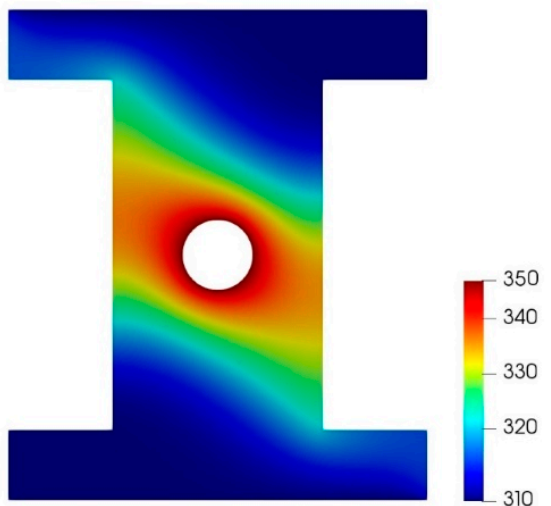

(d)

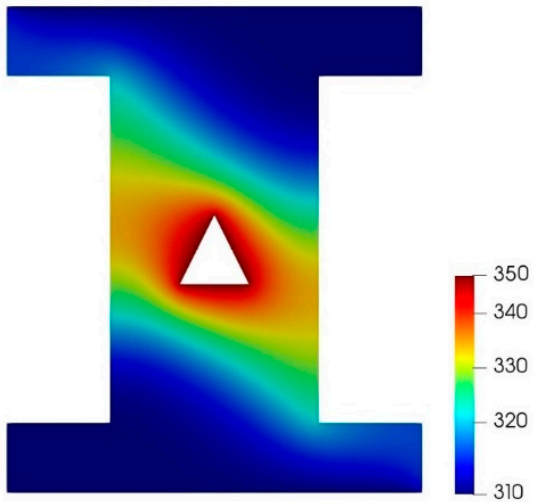

(f)

Figure 6. The temperature contours of $4 \%$ volume of the NF in three different hot blocks in two cases, including sand (a,c,e) and compact metallic powder $(\mathbf{b}, \mathbf{d}, \mathbf{f})$.

Local EG contours of $4 \%$ volume of the NF in three different hot blocks in two cases, including sand (a), (c), (e) and compact metallic powder (b), (d), (f), are shown in Figure 7. The EG rate reached its maximum at the neighborhood of the lids in all cases. This was because of the considerable velocity of the driven lids. However, the EG rate was also much important at the center of the porous cavity in all cases due to the heat flux of the hot blocks. The results showed more uniform EG contours for the compact metallic powder than the sand because of its higher thermal conductivity. 


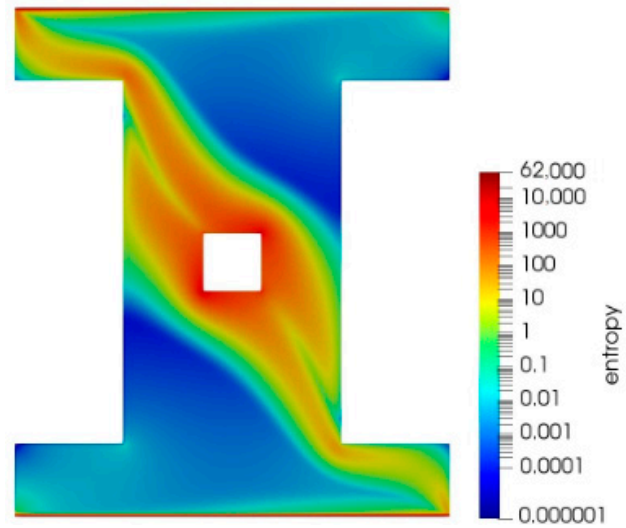

(a)

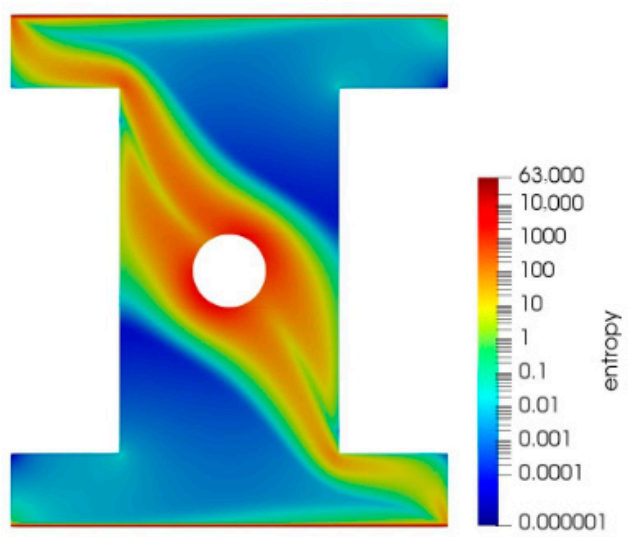

(c)

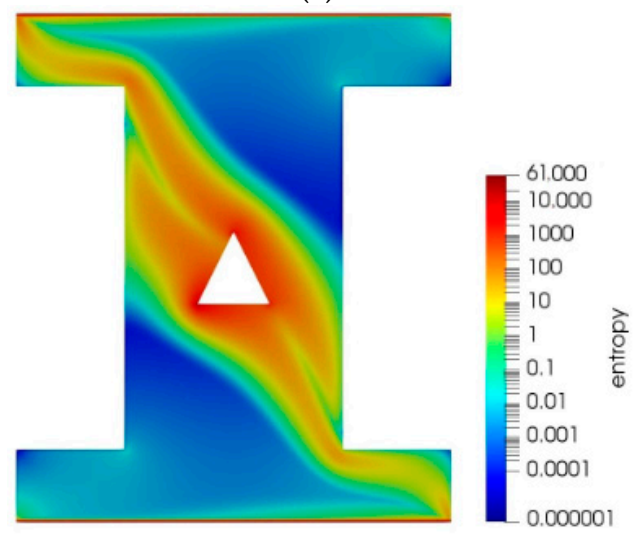

(e)

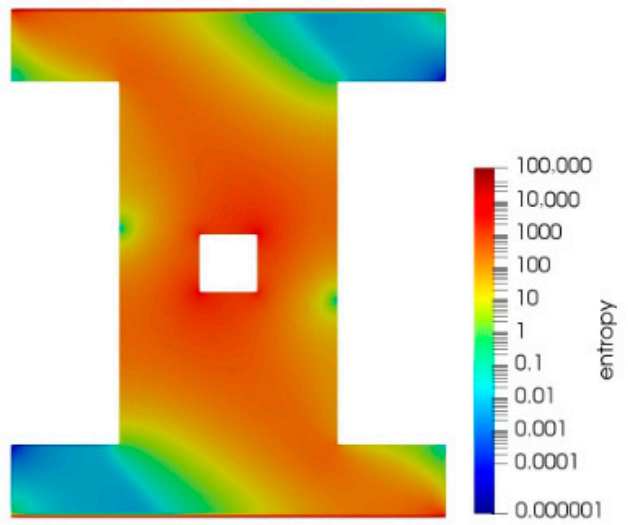

(b)

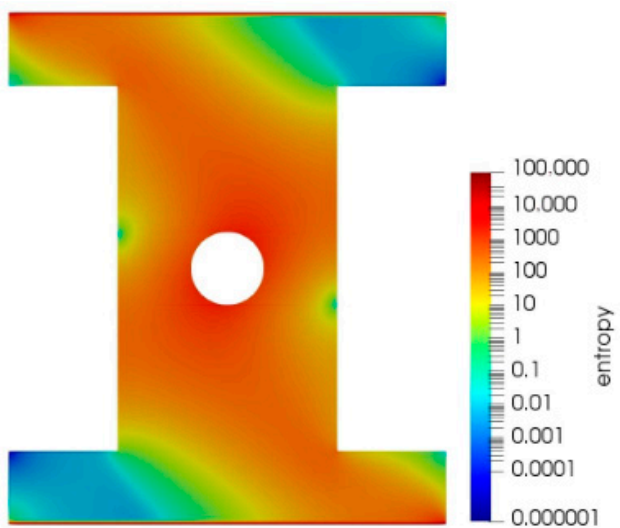

(d)

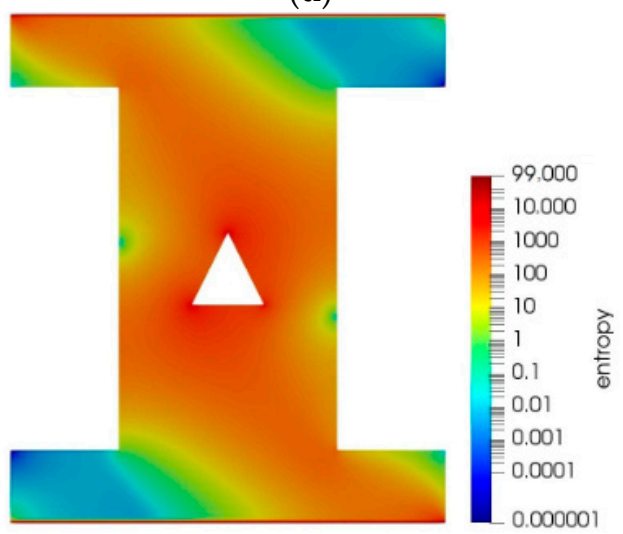

(f)

Figure 7. The EG contours of $4 \%$ volume of the NF in three different hot blocks in two cases, including sand $(\mathbf{a}, \mathbf{c}, \mathbf{e})$ and compact metallic powder $(\mathbf{b}, \mathbf{d}, \mathbf{f})$.

The contours of nanoparticle distribution with different shapes of internal hot blocks for sand (a), (c), (e) and compact metallic powder (b), (d), (f) are shown in Figure 8. It was found that the bottom half of the cavity had a larger density of NP than the upper half due to the buoyancy effect of the existent temperature gradient. This was true for all geometries of the hot blocks located in the sand as the porous material. The NP distribution contours for the compact metallic powder (b), (d), (f) demonstrated a more uniform distribution of the NP in the cavity. However, there was a narrow line elongated from the bottom-right to upper-left of the cavity with a small density of the NP compared to the rest of the cavity. It could be concluded that the forced convection heat transfer considerably affected the NP distribution through this line. As it is shown in Figure 6, the temperature gradient was significant in the sand-based porous case, and it was observed at the periphery of the hot 
block. Therefore, we have a more intense temperature gradient in the sand-based case. Therefore, a higher value of the thermophoresis effect and, consequently, a more important particle migration happened in the sand case. The particle migration also occurred from the hot wall in all cases.

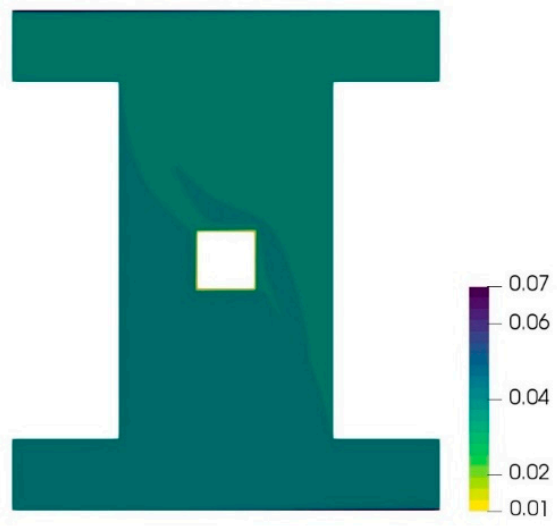

(a)

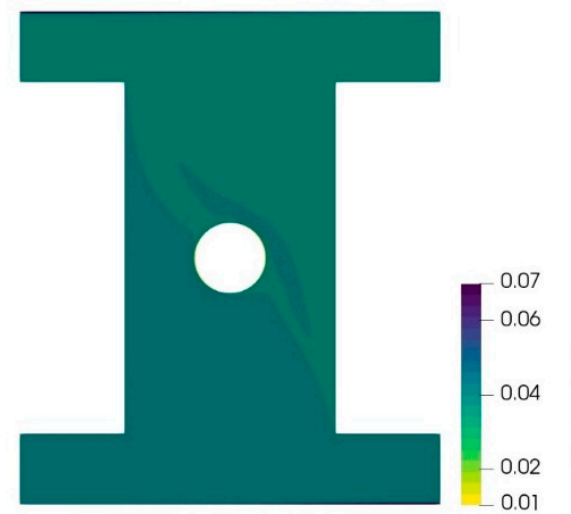

(c)

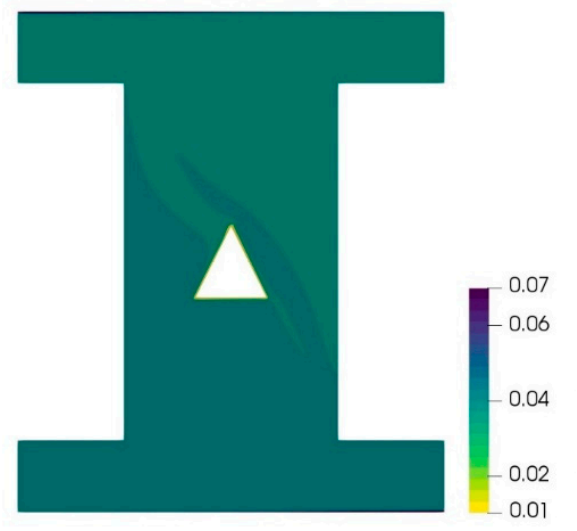

(e)

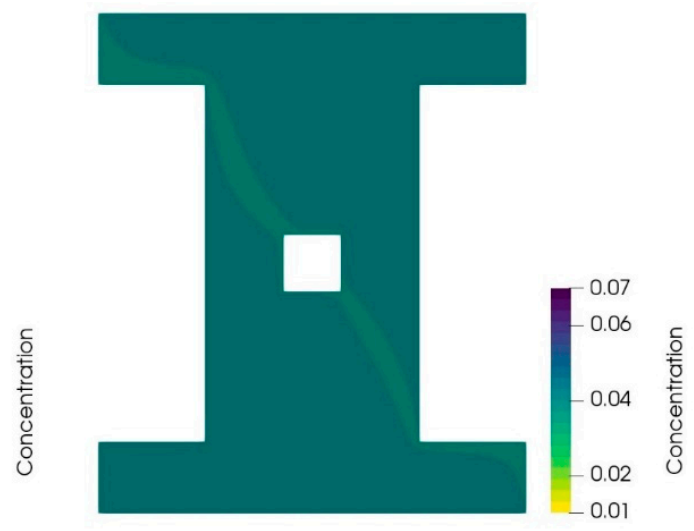

(b)

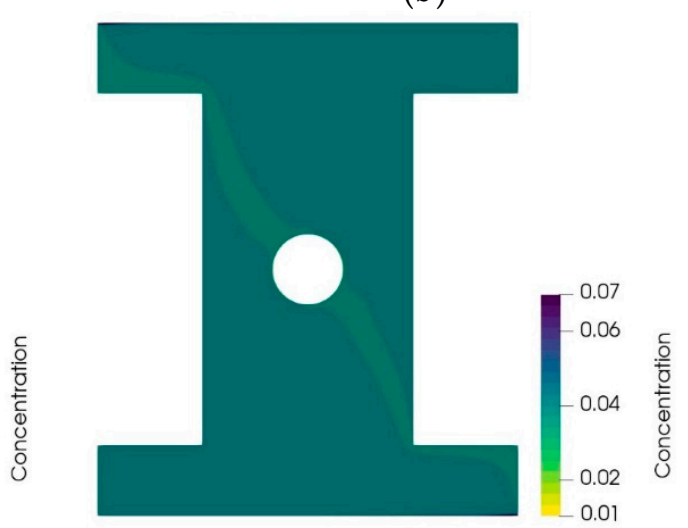

(d)

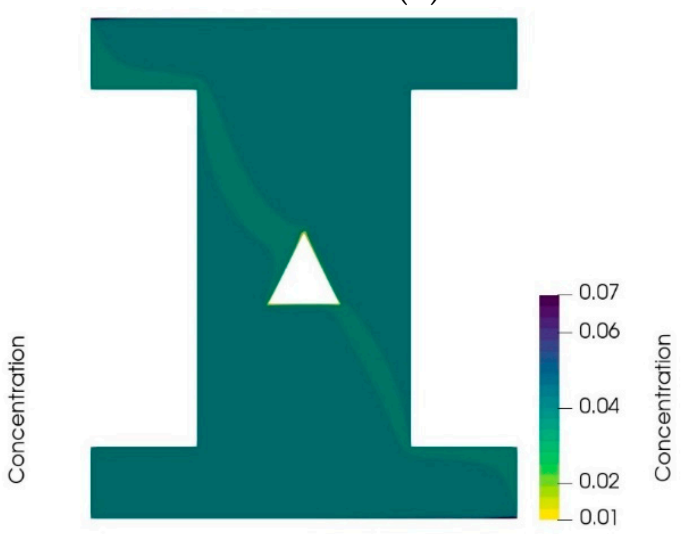

$(\mathbf{f})$

Figure 8. The NP distribution contours of $4 \%$ volume of the NF in three different hot blocks in two cases, including sand $(\mathbf{a}, \mathbf{c}, \mathbf{e})$ and compact metallic powder $(\mathbf{b}, \mathbf{d}, \mathbf{f})$.

The variation of the Nusselt number as a function of volume concentration for the sand porous cavity is shown in Figure 9. It is clear that the average $\mathrm{Nu}$ was enhanced with any increase in the NP volume concentration. The circular hot block also gave the highest $\mathrm{Nu}$ at a given NP volume concentration, while the values for triangular and square hot blocks were relatively similar and considerably lower than those of the circular hot block. However, the maximum enhancement in the average $\mathrm{Nu}$ occurred for the triangular hot 
block (11.93\%), followed by circular (11.79\%) and square (10.30\%) hot blocks, respectively. Seemingly, the enhancements in the average $\mathrm{Nu}$ were relatively the same for all geometries when the sand was employed as a porous solid material.

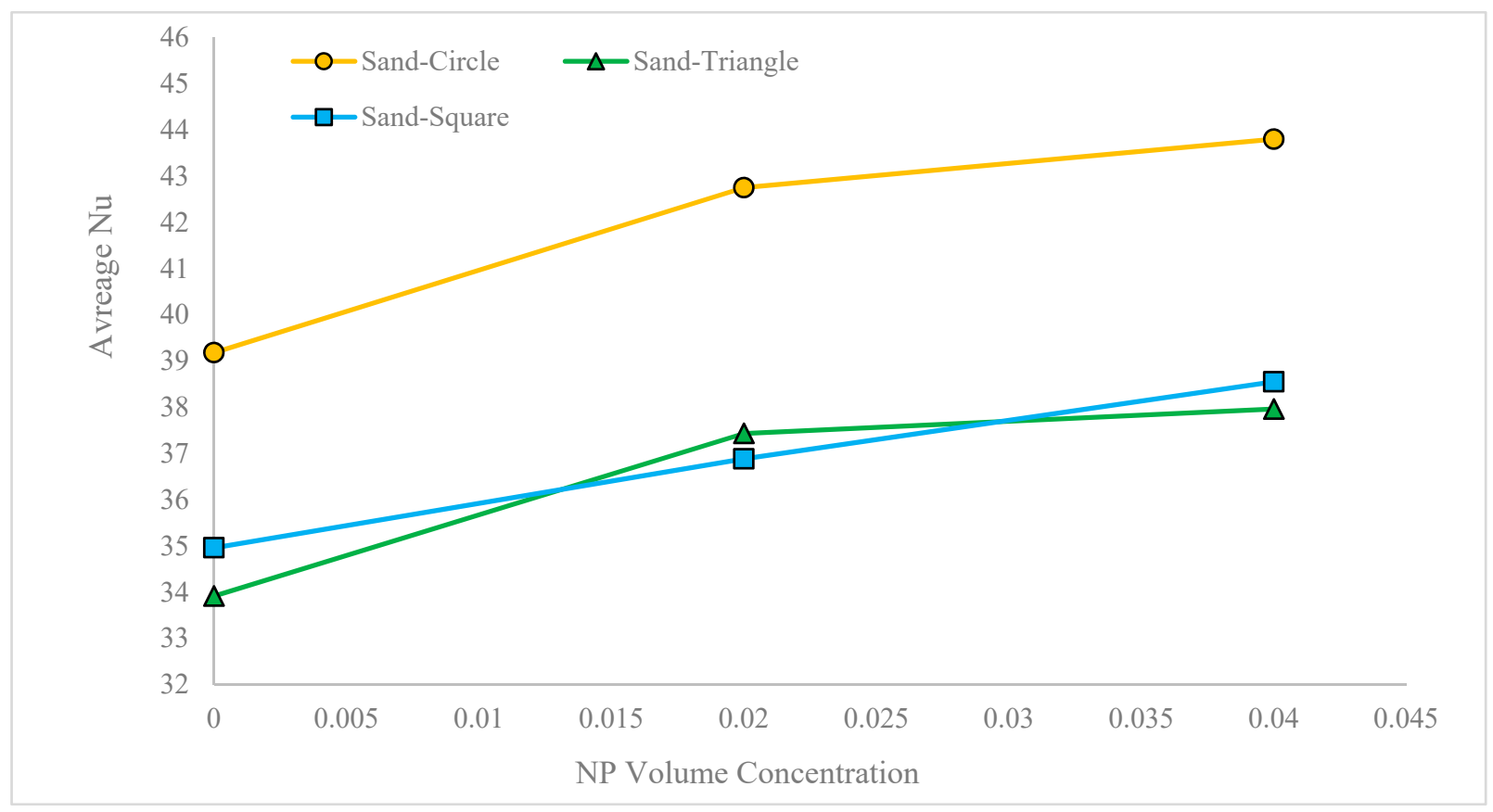

Figure 9. The average $\mathrm{Nu}$ against the NP volume concentration for a sand-based porous cavity with different geometries of hot blocks.

The average Nusselt number against the volume concentration in a metallic powderbased porous medium is shown in Figure 10. First of all, it should be noted that any increase in the NP volume concentration led to enhancing the average $\mathrm{Nu}$ for all geometries of the hot blocks. Nevertheless, the values for the metallic powder were dramatically bigger than those of sand due to the large difference in their thermal conductivities. The circular hot block yielded a much greater value of the average $\mathrm{Nu}$ compared to the square and triangular hot blocks. However, the maximum enhancement in the average $\mathrm{Nu}$ occurred for the circular hot block $(6.15 \%)$, followed by the square $(5.89 \%)$ and triangular $(5.51 \%)$ hot blocks, respectively. Compared with the enhancements in the average $\mathrm{Nu}$ for the sand-based cavity, it seemed that using the NF in a less conductive porous material may lead to more enhancement.

Figure 11 shows the variations of the normalized Nu versus the NP volume concentration for all cases. The normalized $\mathrm{Nu}$ was defined as the ratio of the $\mathrm{Nu}$ at a given NP volume concertation to the $\mathrm{Nu}$ of the base fluid (in which the NP volume concentration was zero). It is clear that the sand-based porous media gave a much higher value of the normalized $\mathrm{Nu}$ compared to the metallic powder-based porous media. 


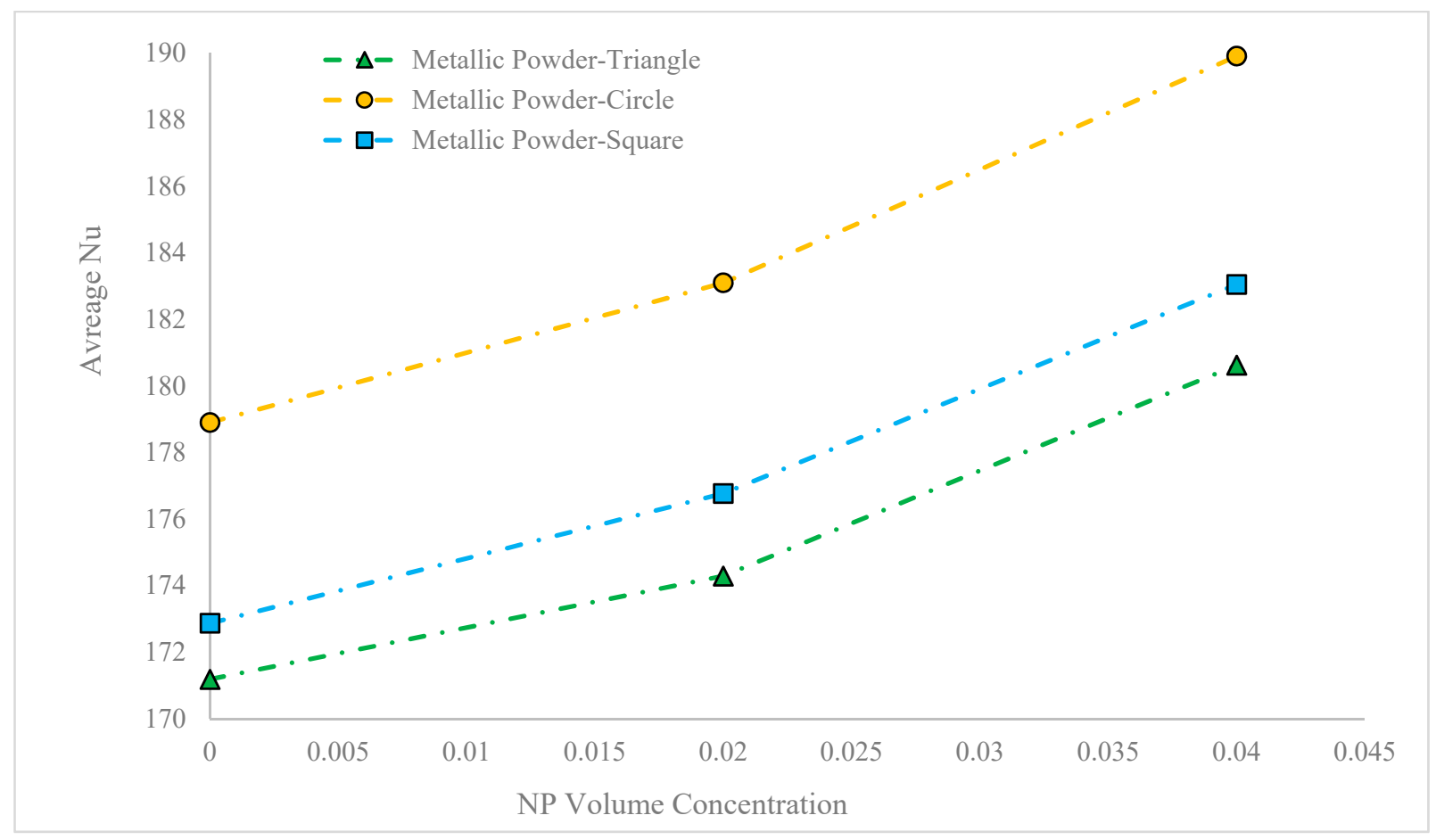

Figure 10. The average $\mathrm{Nu}$ against the NP volume concentration for the metallic powder-based porous cavity with different geometries of hot blocks.

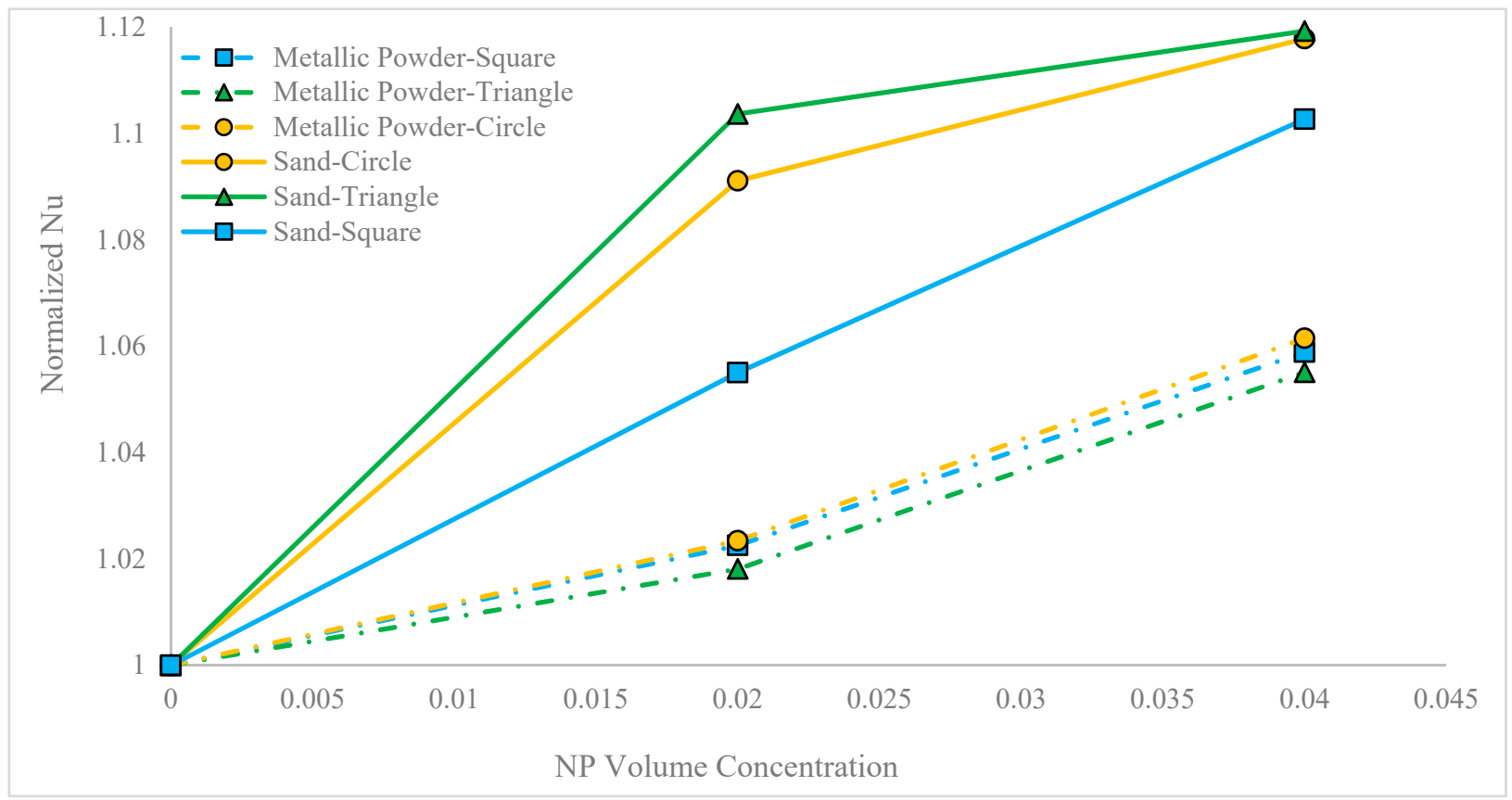

Figure 11. The normalized $\mathrm{Nu}$ against the NP volume concentration for all cases.

The variations of the normalized entropy against the volume concentration for all cases are shown in Figure 12. The normalized entropy was defined as the ratio of entropy at a given NP volume concentration to the entropy of the base fluid (in which the NP volume concentration was zero). Typically, the enhancement in the EG for the sand-based porous media was a much greater one than those of the metallic powder-based porous cavity in all 
geometries of the hot blocks. It means that there was more irreversibility in the sand-based porous media compared to the metallic powder-based porous media.

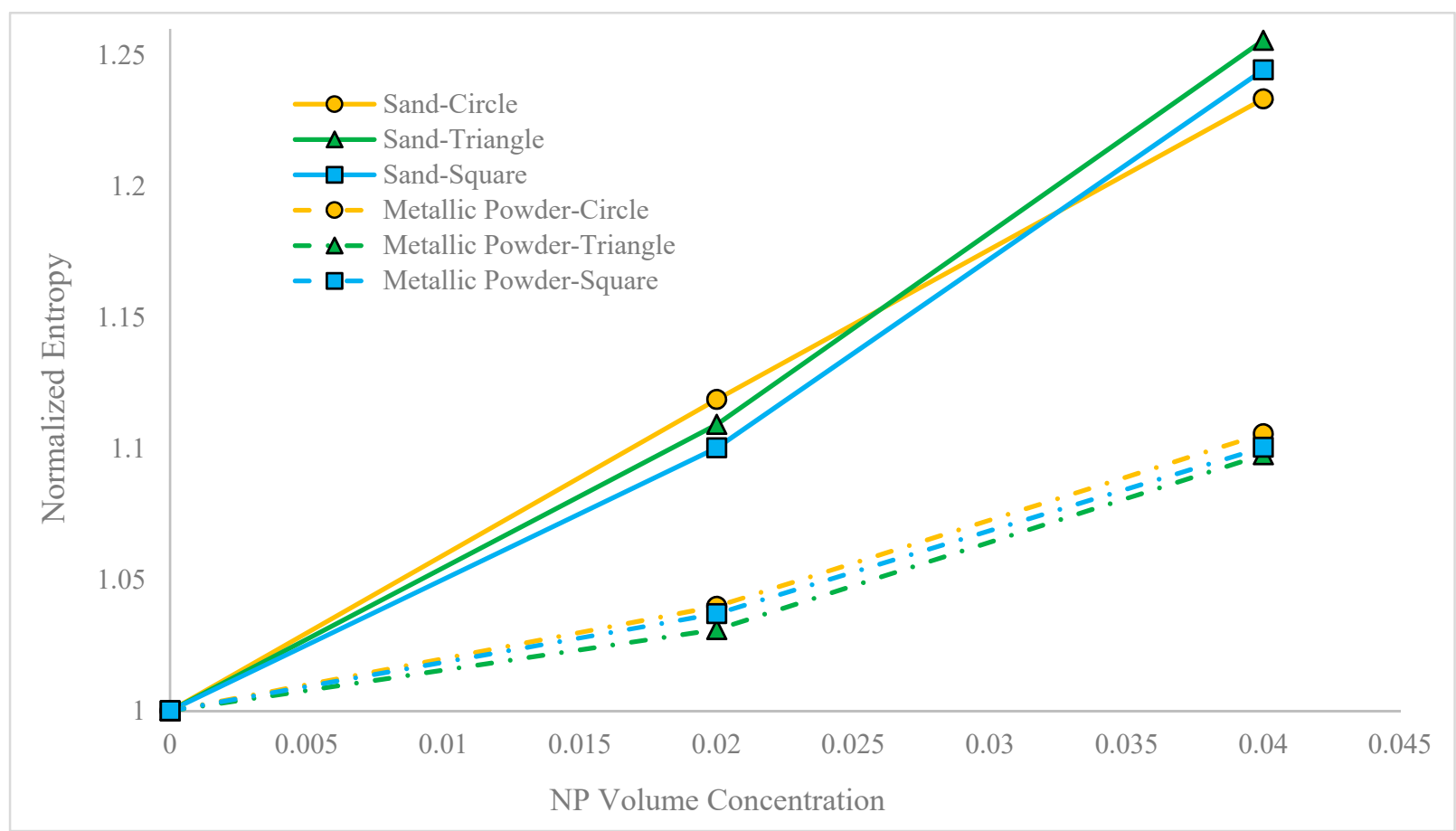

Figure 12. The variations of the normalized entropy against the NP volume concentration for all cases.

Meanwhile, the EG enhancement reached to its maximum value in this study for the triangular hot block $(25.56 \%)$, followed by the square $(24.43 \%)$ and circular $(23.33 \%)$ hot blocks, respectively. On the other side, the maximum EG enhancement in the metallic powder-based porous media occurred in the circular hot block $(10.56 \%)$, followed by the square $(10.04 \%)$ and triangular (9.76) hot blocks, respectively.

Figure 13 represents the thermal performance of different porous cavities with different hot blocks against the NP volume concentration. Generally, the thermal performance reduced with any increase in the volume concentration in all cases.

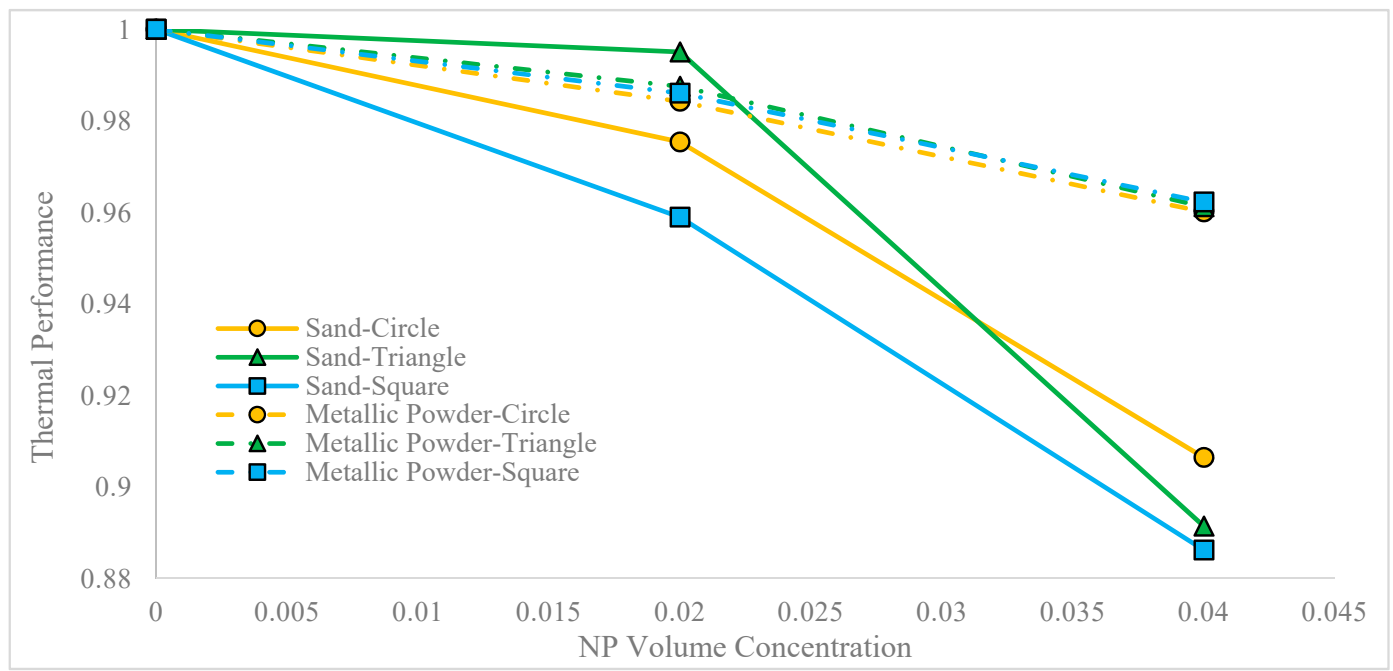

Figure 13. The thermal performance of different porous cavities with different hot blocks as a function of the NP volume concentration. 


\section{Conclusions}

This paper reported a numerical investigation of the mixed convection in an I-shaped porous cavity involving alumina-water NF with different internal hot block shapes and different porous media. It should be noted that the used thermo-fluid configuration was novel. Buongiorno's method with some assumptions was also applied. The most important results are as follows:

- A new model for effective thermal conductivity of the NF was proposed and then was implemented using a multi-variable regression method with an acceptable accuracy.

- The low permeability for the sand-based porous media led to a small temperature distribution around the hot blocks. The compact metallic powder gave a more elongated temperature distribution than those of sand.

- The EG rate was very important at the center of the porous cavity in all cases due to the heat flux of hot blocks. There was a more uniform EG contour for the compact metallic powder than the sand due to its higher thermal conductivity.

- The average $\mathrm{Nu}$ decreased with any decrease in volume concentration. The maximum heat transfer enhancement (11.93\%) occurred for $4 \%$ volume NF in a sand-based porous cavity.

- The $\mathrm{Nu}$ for metallic powder were dramatically greater than those of sand.

- Using the NF in a less conductive porous material might lead to more enhancement in heat transfer. The sand-based porous medium also gave a much higher value of the normalized $\mathrm{Nu}$ compared to the metallic powder-based porous medium.

- The EG for the sand-based porous media was much greater than the other porous medium in all geometries of hot blocks.

- The EG reached its maximum value for the triangular hot block $(25.56 \%)$, followed by the square $(24.43 \%)$ and circular $(23.33 \%)$ hot blocks, respectively. Nevertheless, the maximum EG enhancement in the metallic porous media occurred in the circular hot block $(10.56 \%)$, followed by the square $(10.04 \%)$ and triangular $(9.76)$ hot blocks, respectively.

Author Contributions: Conceptualization, M.M.; formal analysis, R.G. and M.M.; investigation, R.G.; supervision, T.A. and M.S.P.; writing—original draft, M.M.; writing—review and editing, T.A. and M.S.P. All authors have read and agreed to the published version of the manuscript.

Funding: This research received no external funding.

Institutional Review Board Statement: Not applicable.

Informed Consent Statement: Not applicable.

Data Availability Statement: Data sharing not applicable.

Conflicts of Interest: The authors declare no conflict of interest. 


\section{Nomenclature}

\begin{tabular}{|c|c|}
\hline$\vec{V}$ & Velocity vector \\
\hline$\rho_{n f}$ & Density of NF \\
\hline$\mu_{n f}$ & Dynamic viscosity of NF \\
\hline S & Source term for porosity \\
\hline$p$ & Pressure \\
\hline $\mathrm{d}$ & Darcy coefficient \\
\hline$D_{T}$ & Coefficient of the thermophoresis diffusion \\
\hline$D_{B}$ & Coefficient of the Brownian diffusion \\
\hline$K_{b}$ & Boltzmann constant \\
\hline$d_{n p}$ & NP mean diameter \\
\hline$k_{b f}$ & Thermal conductivity of base fluid \\
\hline$k_{n p}$ & Thermal conductivity of NP \\
\hline$S_{g e n}$ & EG \\
\hline$\varepsilon$ & Porosity \\
\hline $\mathrm{u}$ & Velocity in $\mathrm{x}$-direction \\
\hline $\mathrm{v}$ & Velocity in y-direction \\
\hline $\mathrm{f}$ & Forchheimer coefficient \\
\hline K & Permeability \\
\hline$n$ & Normal vector \\
\hline$\beta_{n f}$ & Thermal expansion coefficient of NF \\
\hline$\beta_{b f}$ & Thermal expansion coefficient of the base fluid \\
\hline$\beta_{n p}$ & Thermal expansion coefficient of NP \\
\hline $\mathrm{Nu}$ & $\mathrm{Nu}$ \\
\hline $\mathrm{T}$ & Temperature \\
\hline$\theta$ & Dimensionless temperature \\
\hline$T_{0}$ & Reference temperature (mean temperature) \\
\hline$T_{\text {cold }}$ & Temperature at cold surface \\
\hline$T_{\text {hot }}$ & Temperature at hot surface \\
\hline $\mathrm{C}_{\mathrm{p}, \mathrm{nf}}$ & Heat capacity of NF at constant pressure \\
\hline$k_{e f f}$ & Effective thermal conductivity of NF \\
\hline$k_{\text {solid }}$ & Thermal conductivity of porous media \\
\hline$\rho_{n p}$ & Density of NP \\
\hline$\underline{\rho_{b f}}$ & Density of the base fluid \\
\hline$\varphi$ & NP volume concentration \\
\hline$\mu_{b f}$ & Dynamic viscosity of the base fluid \\
\hline $\mathrm{C}_{\mathrm{p}, \mathrm{np}}$ & Heat capacity of NP at constant pressure \\
\hline$C_{p, b f}$ & Heat capacity of the base fluid at constant pressure \\
\hline
\end{tabular}




\section{References}

1. Choi, S.U.S.; Eastman, J.A. Enhancing Thermal Conductivity of Fluids with Nanoparticles; Argonne National Lab.: Argonne, IL, USA, 1995

2. Maxwell, J.C. Electricity and Magnetism; Oxford University Press: Oxford, UK, 1873.

3. Mohammadpour, J.; Lee, A. Investigation of nanoparticle effects on jet impingement heat transfer: A review. J. Mol. Liq. 2020, 316, 113819. [CrossRef]

4. Kakavand, H.; Molana, M. A numerical study of heat transfer charcteristics of a car radiator involved nanofluids. Heat Transf.-Asian Res. 2018, 47, 88-102. [CrossRef]

5. Sui, D.; Langåker, V.H.; Yu, Z. Investigation of Thermophysical Properties of Nanofluids for Application in Geothermal Energy. Energy Procedia 2017, 105, 5055-5060. [CrossRef]

6. Ghalandari, M.; Maleki, A.; Haghighi, A.; Shadloo, M.S.; Nazari, M.A.; Tlili, I. Applications of nanofluids containing carbon nanotubes in solar energy systems: A review. J. Mol. Liq. 2020, 313, 113476. [CrossRef]

7. Izadi, S.; Armaghani, T.; Ghasemiasl, R.; Chamkha, A.J.; Molana, M. A comprehensive review on mixed convection of nanofluids in various shapes of enclosures. Powder Technol. 2019, 343, 880-907. [CrossRef]

8. Lim, A.E.; Lim, C.Y.; Lam, Y.C.; Taboryski, R.J.; Wang, S.R. Effect of nanostructures orientation on electroosmotic flow in a microfluidic channel. Nanotechnology 2017, 28, 255303. [CrossRef]

9. Molana, M.; Zarrinderafsh, V.; Chamkha, A.J.; Izadi, S.; Rafizadeh, S. Magnetohydrodynamics convection in nanofluids-filled cavities: A review. Heat Transf. 2020, 49, 1418-1443. [CrossRef]

10. Zamzamian, A.; Oskouie, S.N.; Doosthoseini, A.; Joneidi, A.; Pazouki, M. Experimental investigation of forced convective heat transfer coefficient in nanofluids of $\mathrm{Al}_{2} \mathrm{O}_{3} / \mathrm{EG}$ and $\mathrm{CuO} / \mathrm{EG}$ in a double pipe and plate heat exchangers under turbulent flow. Exp. Therm. Fluid Sci. 2011, 35, 495-502. [CrossRef]

11. Buongiorno, J.; Hu, L.W.; Kim, S.J.; Hannink, R.; Truong, B.; Forrest, E. Nanofluids for Enhanced Economics and Safety of Nuclear Reactors: An Evaluation of the Potential Features, Issues, and Research Gaps. Nuclear Technol. 2008, 162, 80-91. [CrossRef]

12. Buongiorno, J.; Hu, L.W.; Apostolakis, G.; Hannink, R.; Lucas, T.; Chupin, A. A feasibility assessment of the use of nanofluids to enhance the in-vessel retention capability in light-water reactors. Nuclear Eng. Des. 2009, 239, 941-948. [CrossRef]

13. Nguyen, C.T.; Roy, G.; Gauthier, C.; Galanis, N. Heat transfer enhancement using $\mathrm{Al}_{2} \mathrm{O}_{3}-\mathrm{water}$ nanofluid for an electronic liquid cooling system. Appl. Therm. Eng. 2007, 27, 1501-1506. [CrossRef]

14. Nam, J.S.; Lee, P.-H.; Lee, S.W. Experimental characterization of micro-drilling process using nanofluid minimum quantity lubrication. Int. J. Mach. Tools Manuf. 2011, 51, 649-652. [CrossRef]

15. Rao, Y. Nanofluids: Stability, phase diagram, rheology and applications. Particuology 2010, 8, 549-555. [CrossRef]

16. Gan, Y.; Lim, Y.S.; Qiao, L. Combustion of nanofluid fuels with the addition of boron and iron particles at dilute and dense concentrations. Combust. Flame 2012, 159, 1732-1740. [CrossRef]

17. Basu, S.; Miglani, A. Combustion and heat transfer characteristics of nanofluid fuel droplets: A short review. Int. J. Heat Mass Transf. 2016, 96, 482-503. [CrossRef]

18. Rostami, J.; Abbassi, A. Conjugate heat transfer in a wavy microchannel using nanofluid by two-phase Eulerian-Lagrangian method. Adv. Powder Technol. 2016, 27, 9-18. [CrossRef]

19. Ghasemi, S.E.; Vatani, M.; Hatami, M.; Ganji, D. Analytical and numerical investigation of nanoparticle effect on peristaltic fluid flow in drug delivery systems. J. Mol. Liq. 2016, 215, 88-97. [CrossRef]

20. Daloglu, A. Study on overall heat transfer coefficient for a rotating cavity type heat exchanger. Int. Commun. Heat Mass Transf. 1999, 26, 861-867. [CrossRef]

21. Singh, H.; Eames, P.C. Correlations for natural convective heat exchange in CPC solar collector cavities determined from experimental measurements. Sol. Energy 2012, 86, 2443-2457. [CrossRef]

22. Bürger, S.; Riciputi, L.; Turgeon, S.; Bostick, D.; McBay, E.; Lavelle, M. A high efficiency cavity ion source using TIMS for nuclear forensic analysis. J. Alloy. Compd. 2007, 444, 660-662. [CrossRef]

23. Lee, L.; Park, H.; Kim, T.S.; Ko, K.H.; Jeong, D.Y. A new sensor for detection of coolant leakage in nuclear power plants using off-axis integrated cavity output spectroscopy. Nuclear Instrum. Methods Phys. Res. Sect. A Accel. Spectrometers Detect. Assoc. Equip. 2012, 678, 8-12. [CrossRef]

24. Laguerre, O.; Amara, S.B.; Flick, D. Experimental study of heat transfer by natural convection in a closed cavity: Application in a domestic refrigerator. J. Food Eng. 2005, 70, 523-537. [CrossRef]

25. Hajmohammadi, M.R. Introducing a $\psi$-shaped cavity for cooling a heat generating medium. Int. J. Therm. Sci. 2017, 121, 204-212. [CrossRef]

26. Alsabery, A.I.; Chamkha, A.J.; Saleh, H.; Hashim, I.; Chanane, B. Effects of finite wall thickness and sinusoidal heating on convection in nanofluid-saturated local thermal non-equilibrium porous cavity. Phys. A Stat. Mech. Appl. 2017, 470, 20-38. [CrossRef]

27. Alsabery, A.I.; Chamkha, A.J.; Hashim, I.; Siddheshwar, P.G. Effects of Nonuniform Heating and Wall Conduction on Natural Convection in a Square Porous Cavity Using LTNE Model. J. Heat Transf. 2017, 139, 122008. [CrossRef]

28. Basak, T.; Roy, S.; Chamkha, A.J. A Peclet number based analysis of mixed convection for lid-driven porous square cavities with various heating of bottom wall. Int. Commun. Heat Mass Transf. 2012, 39, 657-664. [CrossRef]

29. Patterson, J.; Imberger, J. Unsteady natural convection in a rectangular cavity. J. Fluid Mech. 1980, 100, 65-86. [CrossRef] 
30. Tiwari, R.K.; Das, M.K. Heat transfer augmentation in a two-sided lid-driven differentially heated square cavity utilizing nanofluids. Int. J. Heat Mass Transf. 2007, 50, 2002-2018. [CrossRef]

31. Karim, A.; Billah, M.M.; Newton, M.T.; Rahman, M.M. Influence of the Periodicity of Sinusoidal Boundary Condition on the Unsteady Mixed Convection within a Square Enclosure Using an Ag-Water Nanofluid. Energies 2017, 10, 2167. [CrossRef]

32. Mehmood, K.; Hussain, S.; Sagheer, M. Numerical simulation of MHD mixed convection in alumina-water nanofluid filled square porous cavity using KKL model: Effects of non-linear thermal radiation and inclined magnetic field. J. Mol. Liq. 2017, 238, 485-498. [CrossRef]

33. Nithyadevi, N.; Begum, A.S.; Oztop, H.F.; Abu-Hamdeh, N. Mixed convection analysis in heat transfer enhancement of a nanofluid filled porous enclosure with various wall speed ratios. Int. J. Heat Mass Transf. 2017, 113, 716-729. [CrossRef]

34. Hadavand, M.; Yousefzadeh, S.; Akbari, O.A.; Pourfattah, F.; Nguyen, H.M.; Asadi, A. A numerical investigation on the effects of mixed convection of Ag-water nanofluid inside a sim-circular lid-driven cavity on the temperature of an electronic silicon chip. Appl. Therm. Eng. 2019, 162, 114298. [CrossRef]

35. Kadri, S.; Mehdaoui, R.; Elmir, M. A Vertical Magneto-Convection in Square Cavity Containing a $\mathrm{Al}_{2} \mathrm{O}_{3}+\mathrm{Water}_{\mathrm{Nanofluid}}$ Cooling of Electronic Compounds. Energy Procedia 2012, 18, 724-732. [CrossRef]

36. Haddad, O.; Baïri, A.; Alilat, N.; Bauzin, J.G.; Laraqi, N. Free convection in ZnO-Water nanofluid-filled and tilted hemispherical enclosures containing a cubic electronic device. Int. Commun. Heat Mass Transf. 2017, 87, 204-211. [CrossRef]

37. Khan, W.A.; Pop, I. Boundary-layer flow of a nanofluid past a stretching sheet. Int. J. Heat Mass Transf. 2010, 53, 2477-2483. [CrossRef]

38. Nield, D.A.; Bejan, A. Convection in Porous Media, 3rd ed.; Springer: Berlin/Heidelberg, Germany, 2006.

39. Molana, M.; Ghasemiasl, R.; Armaghani, T. A different look at the effect of temperature on the nanofluids thermal conductivity: Focus on the experimental-based models. J. Therm. Anal. Calorim. 2021, 1-25. [CrossRef]

40. Minea, A.A.; Buonomo, B.; Burggraf, J.; Ercole, D.; Karpaiya, K.R.; Di Pasqua, A.; Sekrani, G.; Steffens, J.; Tibaut, J.; Wichmann, N.; et al. NanoRound: A benchmark study on the numerical approach in nanofluids' simulation. Int. Commun. Heat Mass Transf. 2019, 108, 104292. [CrossRef]

41. Saghir, M.Z.; Ahadi, A.; Mohamad, A.; Srinivasan, S. Water aluminum oxide nanofluid benchmark model. Int. J. Therm. Sci. 2016, 109, 148-158. [CrossRef]

42. Ho, C.J.; Liu, W.K.; Chang, Y.S.; Lin, C.C. Natural convection heat transfer of alumina-water nanofluid in vertical square enclosures: An experimental study. Int. J. Therm. Sci. 2010, 49, 1345-1353. [CrossRef]

43. Nithiarasu, P.; Ravindran, K. A new semi-implicit time stepping procedure for buoyancy driven flow in a fluid saturated porous medium. Comput. Methods Appl. Mech. Eng. 1998, 165, 147-154. [CrossRef]

44. Nithiarasu, P.; Seetharamu, K.; Sundararajan, T. Natural convective heat transfer in a fluid saturated variable porosity medium. Int. J. Heat Mass Transf. 1997, 40, 3955-3967. [CrossRef]

45. Buongiorno, J. A Non-Homogeneous Equilibrium Model for Convective Transport in Flowing Nanofluids. Heat Transf. Summer Conf. 2005, 47322, 599-607. [CrossRef]

46. Armaghani, T.; Ismael, M.A.; Chamkha, A.J. Analysis of entropy generation and natural convection in an inclined partially porous layered cavity filled with a nanofluid. Can. J. Phys. 2017, 95, 238-252. [CrossRef]

47. Mahian, O.; Kolsi, L.; Amani, M.; Estellé, P.; Ahmadi, G.; Kleinstreuer, C.; Marshall, J.S.; Siavashi, M.; Taylor, R.A.; Niazmand, H.; et al. Recent advances in modeling and simulation of nanofluid flows-Part I: Fundamentals and theory. Phys. Rep. 2019, 790, 1-48. [CrossRef]

48. Khanafer, K.; Vafai, K. A Critical Synthesis of Thermophysical Characteristics of Nanofluids. In Nanotechnology and Energy; CRC Press: Boca Raton, FL, USA, 2017; pp. 279-332.

49. Patel, H.E.; Sundararajan, T.; Das, S.K. An experimental investigation into the thermal conductivity enhancement in oxide and metallic nanofluids. J. Nanoparticle Res. 2010, 12, 1015-1031. [CrossRef]

50. Davis, G.D.V. Natural convection of air in a square cavity: A bench mark numerical solution. Int. J. Numer. Methods Fluids 1983, 3 , 249-264. [CrossRef] 